\title{
Weather and traffic accidents in Montreal, Canada
}

\author{
Mircea-Paul Andreescu ${ }^{1}$, David B. Frost ${ }^{2, *}$ \\ 'McGill University, 805 Sherbrooke St. W., Montreal, Quebec H3A 2K6, Canada \\ ${ }^{2}$ Concordia University, 1455 de Maisonville Blvd West, Montreal, Quebec H3G $1 \mathrm{M} 8$, Canada
}

\begin{abstract}
The impact of weather conditions on traffic accidents is an insufficiently understood and poorly quantified phenomenon in Canada, and recent research results reflect conditions that are not entirely characteristic of the Canadian climatic setting. This study analyzed the effects of rain, mean temperature and snow on automobile accidents in Montreal, Canada, from 1990 to 1992. Three time frames were used, monthly, annual and the entire study period. All 3 weather variables impacted road accidents significantly. Snow was shown to be the leading variable, as the number of accidents increased sharply with increased snowfalls. This finding is important in light of recent provincial and municipal proposals to reduce spending on winter snow clearing as a way of cutting operating costs.
\end{abstract}

KEY WORDS: Traffic accidents - Montreal Snow

\section{INTRODUCTION}

The application of applied climatological expertise to the field of transportation has tended to concentrate on the air and marine components, with relatively little attention being accorded to roads. Such consideration as has been given has tended to concentrate on the engineering requirements of road and highway construction rather than upon the disruption of transport flow that may result from adverse weather conditions.

A considerable quantity of personal and anecdotal evidence exists about the likelihood of road disruptions during extreme weather, but little quantitative information has been forthcoming. However, data relating to road accidents are widely available, but have received surprisingly little analysis with respect to weather. Perhaps the complexity involved in establishing the exact cause-and-effect relationship in traffic accidents acts as an obstacle, because road accidents are the result of an intricate driver-vehicleenvironment matrix. The task becomes more arduous when attempting to determine the dominant component, particularly when dealing with daily aggregate

\footnotetext{
-Addressee for correspondence.

E-mail: dfrost@vaxc2.concordia.ca
}

data, where, for instance, there is no certainty that precipitation and accidents occur at the same time.

Most previous studies have concentrated on precipitation, and particularly rain, due to the nature of the precipitation in the areas studied. In Canada, however, both snow and rain hazards are widely distributed and, due to the different climatic environments in some regions, require assessment on a regional level as called for by Andrey \& Olley (1990). This study responds to that call by presenting a quantitative assessment of the effects of temperature, rain and snow on vehicle accidents in Montreal, Quebec, Canada, for the 3 yr period 1990-1992. These accidents represent about one third of those occurring in the Province of Quebec. For 1989, it was estimated that all vehicle accidents in the province cost $\$ 2.63$ billion (\$ Canadian) (Bordeleau 1993).

\section{PREVIOUS WORK}

The overall effects of temperature on road accidents have been found to vary from no definable relationship (Rooney 1967) to low temperatures being associated with more accidents (Orne \& Yang 1972) and a greater level of disruption (de Freitas 1975). 
Palutikof (1991) states that rain is the leading weather variable responsible for traffic deaths, while Sherretz \& Farhar (1978) found a positive linear relationship between accidents and quantity of rain. When rain is falling, accident rates have been found to increase by $6 \%$ (Brotsky \& Hakkert 1988), 22\% (Smith 1982), and as much as 52\% (Codling 1974). Satterthwaite (1976) reported that rainy days experienced double the accident rate of dry days, and Campbell (1971) showed accident rates on dry versus wet surfaces were 2.2 times higher on wet roads. On wet road days, accident risk was found to be 3 times greater by Brotsky \& Hakkert (1988); in accordance Codling (1974) and Smith (1982) found that $31 \%$ and $44 \%$ respectively of all injury accidents occurred on such days. Over half of these increased rates occurred while rain was actually falling.

Haghighi-Talab (1973) and Bertness (1980) found that the effects of falling rain were greatest in urban areas but that accidents were more serious in less densely settled localities where vehicle speeds are generally higher on open roads. Neither found an association with rainfall intensity. Conversely, Sherretz \& Farhar (1978) found the risk of a traffic accident to be greater in heavy rain.

Rooney (1967) and de Freitas (1975) considered the effects of snow on roads within wider studies of the overall effects of snow. Both concluded that urban transportation is the sector most affected by snow and each suggested threshold depths beyond which the disruption reached major proportions. The timing of the snowfall in relation to rush hours was acknowledged to be critical to disruption. Codling (1974) reported that the injury accident rate doubled on snow days, but Smith (1982) showed only a $2.2 \%$ increase in the number of road accidents. Other authors recorded so few snow days that they could generate no valid results.

Geographically, these studies are limited to North America and Great Britain, with the exception of Brotsky \& Hakkert (1988), who compared conditions in Haifa, Israel, with data for a portion of the U.S. east coast. In Canada, de Freitas (1975) considered Montreal, Quebec City, Toronto and Regina while Andrey \& Olley (1990) focused on Edmonton. This is disappointing as there are no truly tropical studies nor are there many from areas with prolonged snow and ice. Although several studies from the northern United States and the study by Andrey \& Olley (1990) cover areas with prolonged cold, none of these areas approach Montreal's unique blend of cold temperatures and heavy snowfall. These studies also span 3 decades during which automotive technology has altered greatly with the rise in use of front-and all-wheel drive cars, radial belted tires, disc brakes, and now anti-lock braking and traction-control systems.

\section{DATA AND METHODS}

Aggregate daily numbers of traffic accidents were obtained from the Société de l'Assurance Automobile du Québec (SAAQ) for the Island of Montreal, Province of Quebec, Canada, for the years 1990-1992. The island, approximately $520 \mathrm{sq} \mathrm{km}$ in extent, is centred on $46^{\circ} \mathrm{N}, 75^{\circ} \mathrm{W}$ and had a population of approximately 1750000 people in 1991. Speed limits for most of the area under study are $50 \mathrm{~km} \mathrm{~h}^{-1}$ but expressways and autoroutes permit speeds ranging from 70 to $100 \mathrm{~km} \mathrm{~h}^{-1}$.

The City of Montreal and 26 other on-island municipalities comprise the Montreal Urban Community (MUC), which is responsible for police services throughout the Island, with the exception of the autoroutes, which are policed by the provincial force, the Surété du Québec (SQ). The SAAQ data is aggregated by day from the MUC and SQ police reports, which must be filed whenever an accident occurs involving at least 1 moving vehicle and where bodily injury exists and/or material damage, as determined by the attending police officer, exceeds $\$ 500$. Accidents are classified as 'fatal' if a fatality occurs within $7 \mathrm{~d}$ of the accident, 'serious' if the overnight hospitalisation of a victim is necessary, 'light' if a victim requires medical attention but does not remain in hospital, and 'material only' if damage to a vehicle exceeds $\$ 500$ but no one involved requires medical attention (SAAQ 1993). Thus, this data set does not provide information about the range of damage/cost sustained by the vehicle(s) involved and, particularly, it does not cover so called 'fender benders' where the damage is so small that neither party wishes to notify their insurers or the police. Also, the data set does not specify the time of the accident or any other circumstances.

For 1992, numbers of vehicles passing certain counting points on the island's autoroutes were obtained from the Ministère des Transports du Québec (Québec 1992). However, the data was incomplete at all sites and could only be used in the most general way to document the weekly and seasonal variation in traffic volume in that year. Fig. 1 shows the relationship between traffic density at one autoroute site and the total number of accidents each month. January and February of that year strikingly illustrate the extent to which accident numbers rise in winter in spite of sharply decreased traffic volumes.

Meteorological data were obtained for the first order meteorological station maintained at Dorval International Airport by the Atmospheric Environment Service of Environment Canada. Daily values of temperature, humidity, precipitation, cloud cover, wind speed and direction are published monthly and annually (AES 1991, 1992, 1993). Mean daily air temperature, 


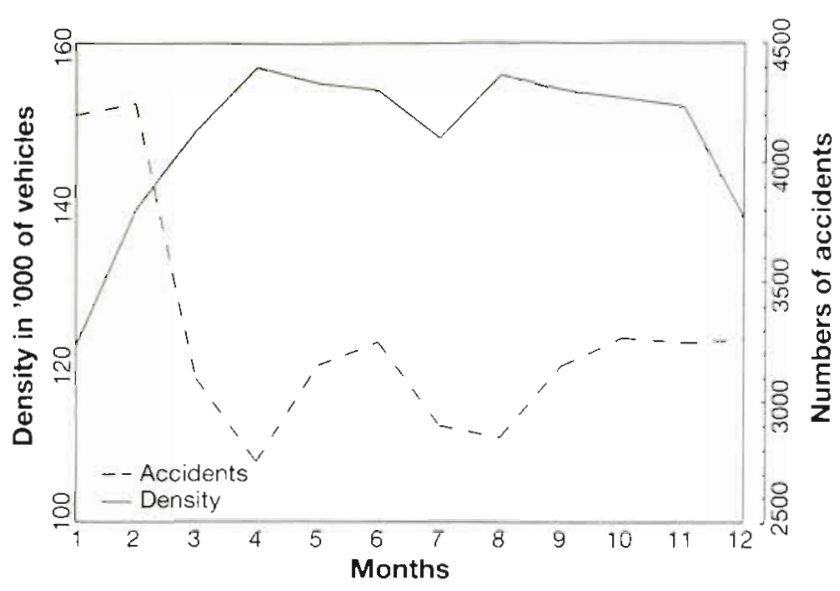

Fig. 1 Montreal, Canada, 1992, mean daily traffic density by month (Autoroute 40, St.-Laurent counting site) and numbers of accidents per month

the arithmetic average of the maximum and minimum temperatures, was used together with daily amounts of rain and snow. Dorval is located $8 \mathrm{~km}$ west of the city centre in suburban and topographic conditions representative of the greater part of the Island.

Initial investigations showed few systematic relationships with the different severities of accident. It was felt that many factors determine the severity of an accident or the degree of injury to occupants, including speed, use of seat-belts, size of vehicle and the presence/absence of roadside obstacles. It was decided to combine all accidents into the total number of accidents per day.

The total number of traffic accidents per day varies greatly with the day of the week and the scattered daily traffic density statistics for 1992 display broadly similar weekly patterns; rising values from Monday to a peak on Friday with sharply reduced numbers on Saturday and Sunday. To remove this factor, average numbers of accidents were calculated for each day of the week using the entire 3 yr data set. Then, differences from the appropriate mean were determined for each individual day. This removal of the weekly cycle from the accident data also acts to eliminate the effects of the weekly cycle of traffic density as well. Throughout the remainder of this paper, this difference from the daily mean will be meant whenever number of accidents is mentioned.

Correlation coefficients and regression equations were calculated for each year and for the entire $3 \mathrm{yr}$ period, with the number of accidents as the dependant variable. Temperature, rainfall and snowfall were the independant variables. Values were accepted as significant at the $0.05 \%$ level. It was appreciated that the relationship between the variables was not necessarily linear. This was investigated by plotting monthly scat- tergrams of number of accidents versus the meteorological variables

Finally, the 'difference of means' test was used to compare mean accident rates on dry days and days with precipitation. To offset partially the effects of ice on the road, the data were divided into 2 series, that with temperatures above freezing and that with temperatures below. The significance of the difference between means was established by the $t$-test.

\section{RESULTS}

Table 1 summarizes the climate of the 3 years studied; 1992 was appreciably cooler than 1990 or 1991 1990 was much wetter than average and 1991 had the most snow. However all years had less snow that the long term average, perhaps due to the increasing urban heat island causing more precipitation to fall as rain rather than as snow.

The total number of traffic accidents fell from 1990 to 1992 by about $11 \%$ and this decline encompassed all classes of accident except the 'serious' category, for which the most were recorded in 1991. This decline was equally distributed across the days of the week, with Monday showing the sharpest decline.

A strong weekly cycle in the number of accidents was present throughout the 3 years. Mondays, Tuesdays and Wednesdays had almost equal numbers of accidents, Thursdays had considerably more and Friday recorded the peak number. Saturday had less accidents than Friday while Sunday had the lowest level in the week. The traffic density statistics, only available for 1992, showed peak densities on Fridays, but revealed lowest densities in peripheral locations on Saturdays and in central areas on Sundays.

Over the entire 3 yr period, the relationships between each of the 3 meteorological variables and the number of accidents were significant at the $0.005 \%$ level. The correlation coefficient between accidents and snow was +0.48 and between accidents and rain was +0.27 , while with temperature the coefficient was -0.29 . This

Table 1. Climatic conditions in Montreal for the period 1990-1992. Note: snowfall is depth of snow rather than the water equivalent. Thus rainfall and snowfall do not add up to total precipitation

\begin{tabular}{|lcccc|}
\hline Year & $\begin{array}{c}\text { Mean } \\
\text { annual } \\
\text { temp. }\left({ }^{\circ} \mathrm{C}\right)\end{array}$ & $\begin{array}{c}\text { Annual } \\
\text { rainfall } \\
(\mathrm{mm})\end{array}$ & $\begin{array}{c}\text { Annual } \\
\text { snowfall } \\
(\mathrm{cm})\end{array}$ & $\begin{array}{c}\text { Total } \\
\text { annual } \\
\text { prec. }(\mathrm{mm})\end{array}$ \\
\hline 1990 & 7.3 & 928 & 179 & 1112 \\
1991 & 7.1 & 710 & 195 & 913 \\
1992 & 5.5 & 790 & 174 & 951 \\
100 Yr mean & 6.2 & 723 & 235 & 946 \\
\hline
\end{tabular}


Table 2. Annual values for 1990-1992 for the number of accidents and the annual correlation coefficients for daily accident numbers regressed upon combinations of independant variables

\begin{tabular}{|lccc|}
\hline & 1990 & 1991 & 1992 \\
\hline Total accidents & & 4.0560 & 39412 \\
Peak accident month & December & January & February \\
Peak wet accident month & October & January & January \\
Snow regression & Significant $(r=0.64)$ & Significant $(r=0.46)$ & Significant $(r=0.39)$ \\
Rain regression & Significant $(r=0.24)$ & Significant $(r=0.20)$ & Significant $(r=0.37)$ \\
Mean temperature regression & Not significant $(r=0.03)$ & Significant $(r=-0.23)$ & Significant $(r=-0.36)$ \\
Snow with mean temperature regression & Not significant $(r=0.64)$ & Not significant $(r=0.49)$ & Significant $(r=0.58)$ \\
Rain with mean temperature regression & Not significant $(r=0.24)$ & Significant $(r=0.33)$ & Significant $(r=0.43)$ \\
& & & \\
'Days when rain and/or snow was measured & & & \\
\end{tabular}

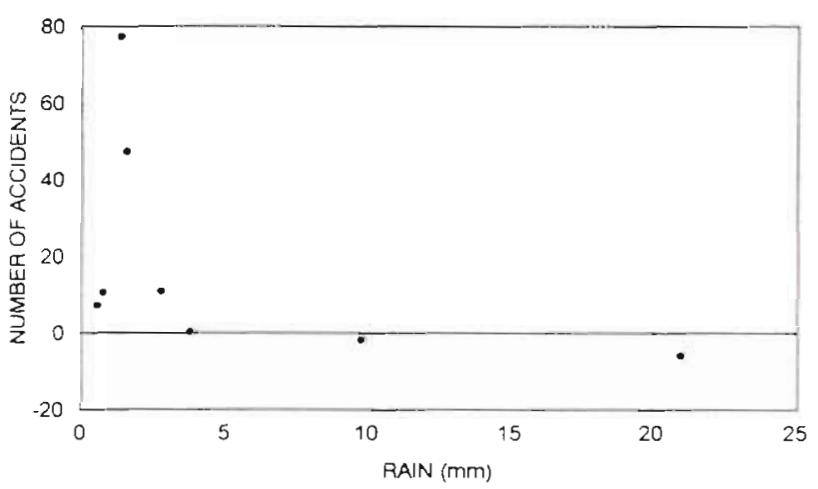

Fig. 2. Montreal, February 1990, number of accidents on days with rainfall vs daily rainfall. Note the large number of accidents on days with low rainfall compared to less-thanexpected numbers of accidents on high rainfall days

is to be expected at the annual or multi-annual time scale as snow, a more highly correlated cause of accidents than rain, only occurs at low temperatures.

When considering annual data for the individual years (see Table 2 ), both snow and rain were positively associated with the number of accidents each year, but temperature, on the other hand, while negatively associated in 1991 and 1992, exhibited no relationship in 1990. Adding temperature to either precipitation variable improved both in 1992, neither in 1990, and rain alone in 1991.

The monthly scattergrams showed a strong positive relationship between numbers of accidents and amount of snow in late winter and early spring, and between numbers of accidents and amount of rainfall in summer months. In winter, however, there were large numbers of accidents at low rainfall quantities and fewer accidents on days with large rainfalls; see, for example, Fig. 2. Temperature at the monthly scale was not as significant a variable, but displayed a seasonal pattern of positive relationships in summer and negative relationships in winter.
Table 3. Mean additional number of accidents on days with precipitation compared to dry days by year

\begin{tabular}{|ccc|}
\hline Year & Snow & Rain \\
\hline 1990 & +26 & +20 \\
1991 & +35 & +19 \\
1992 & +42 & +16 \\
\hline
\end{tabular}

Table 3 documents a significant change in the pattern of accidents over the $3 \mathrm{yr}$ period. Although Table 2 shows that the total number of accidents fell considerably over the 3 yr period and the numbers of accidents on dry days also declined steadily, as did the numbers of accidents on days with rain, there has been a major increase in the number on snowy days. It is clear that snow is the major meteorological variable of concern.

\section{DISCUSSION}

The minor role of air temperature (Fig. 3) demonstrated in this study agrees with Rooney's (1967) results and with the general point made by de Freitas (1975) that temperature is a modifier of accident conditions rather than a root cause. The seasonal pattern of increased accidents with decreasing temperature in winter can be attributed to snow and freezing rain. The reverse in summer is in accordance with aspects of the concept of a thermal comfort range. When temperatures are beyond the upper limit of this range, those driving un-airconditioned vehicles may display less good judgement, and irritability and reaction times increase. Also it should be noted that traffic volumes are highest in summer months. The stronger association with temperature in late winter and early spring, however, requires some explanation. At this time the number of vehicles on the road increases as those in 


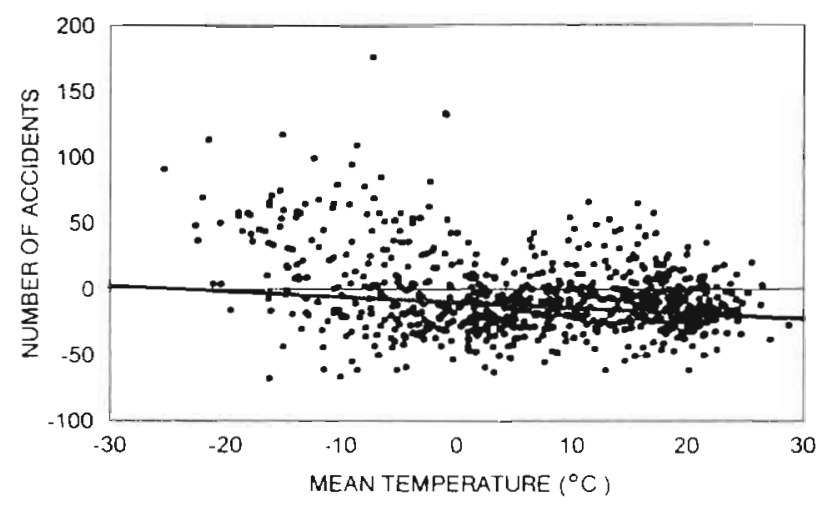

Fig. 3. Montreal, 1990-1992, number of accidents per day vs mean daily temperature, including the best fit linear regression line, $r=-0.29$

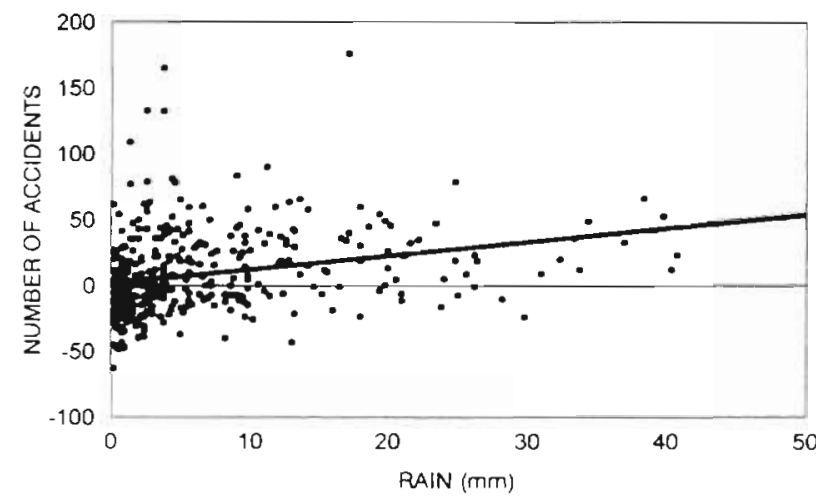

Fig. 4. Montreal, 1990-1992, number of accidents per day vs ranfall amount on days with rain, including the best fit linear regression line, $r=0.27$

winter storage are brought back into use, but, probably more importantly, many motorists remove their winter tires too soon. Thus there are more drivers and vehicles on the road unprepared for icy or snowy conditions. In addition, melting snow in spring can produce wet roads on otherwise dry days, and the warmer the day, the more water accumulates. This water is frequently unable to infiltrate into the ground due to problems of frozen soil and may itself freeze on the road surface at night.

Annually, rain is as important a cause of accidents as snow, but only because there are more rain days than snow days. As rain amounts increase so do numbers of accidents (see Fig. 4). This finding agrees with those of Sheretz \& Farhar (1978) and Smith (1982). Veith (1983) suggests that depth of water on the road surface may be the cause and Moore \& Humphreys (1972) have suggested developing more porous road surfaces. Certainly, drainage problems are acute during strong summer convective storms when large quantities of water

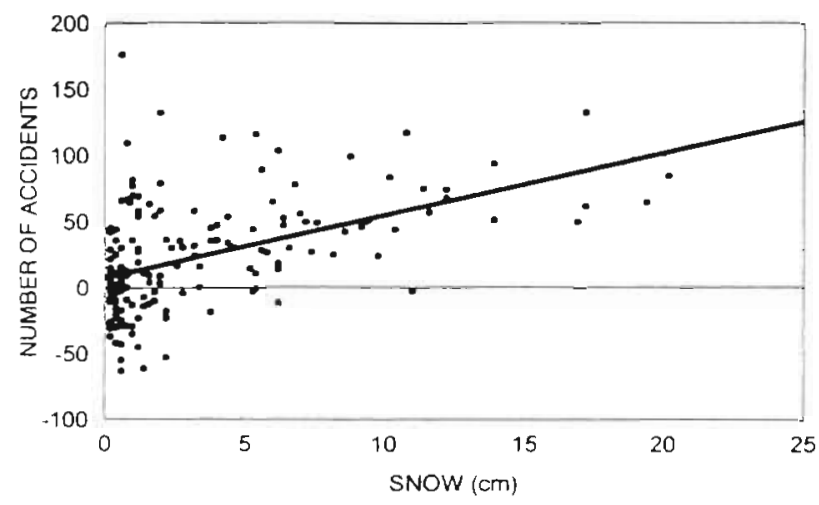

Fig. 5. Montreal, 1990-1992, number of accidents per day vs snowfall amount on days with snow, including the best fit linear regression line, $\mathrm{r}=0.48$

fall in very short time periods, although reduced visibility may be equally important.

Freezing rain, where liquid precipitation freezes on contact with a frozen ground surface, is a special hazard. Other special circumstances that may lead to unexpectedly icy roads include condensation from warm water bodies and other sources of humidity freezing on below-zero road surfaces. These situations require the prompt spreading of sand, salt or other melting agents.

Each municipality and the Ministère de Transport du Québec-responsible for the area's autoroutes has its own snow clearance programme. For example the Ministère de Transport starts ploughing and spreading salt as soon as snow begins to fall (Québec 1993). By contrast, the City of Montreal begins to spread salt immediately on major roads and within $30 \mathrm{~m}$ of stop signs on side streets. Ploughing does not commence until $2.5 \mathrm{~cm}$ of snow has accumulated (Montréal 1992). During a recent strike by the City of Montreal workers, this threshold was increased to $9 \mathrm{~cm}$.

A comparison of the mean numbers of accidents on dry days versus those with less than $2.5 \mathrm{~cm}$ of snow suggests that 20 more accidents occur on these snow days than on the dry days. A part of that increase could be attributable to the limited nature of the City of Montreal's initial snowfall response.

Figs. $4 \& 5$ show a wide range of numbers of accidents at low precipitation values. In part, this can be attributed to the time of the precipitation vis-à-vis heavy traffic periods. Larger amounts of snow, in particular, take many hours to fall and must disrupt working hours. de Freitas (1975) suggested that the number of accidents should fall in very large storms as people leave their vehicles and use public transport. Fig. 5 shows no reduction in the number of accidents during deeper snowfalls. 


\section{CONCLUSION}

This study has examined the role of temperature and precipitation as it affects automobile accidents in a cool mid-latitude continental environment. Although rain has been shown to be associated with an increase in the number of accidents compared to dry days, the study has particularly highlighted the role of snow. Even though the population of Montreal is accustomed to driving in snowy conditions for at least 4 mo a year, the accident rate continues to be highest on snow days. Most worryingly, the number of accidents on snow days is increasing.

The study is particularly timely in Canada as many jurisdictions are seeking to reduce their expenditures and a number, such as the Province of Ontario, have indicated that reduced snow removal will be one area of savings. If such reductions do indeed occur, the cost to the travelling public in terms of damaged vehicles can be expected to rise, as can journey times and cancelled travel. Clearly, additional studies are needed elsewhere in Canada to ascertain whether the relationships outlined above apply throughout the country.

\section{LITERATURE CITED}

AES (Atmospheric Environment Service) $(1990,1991,1992)$ Annual meteorological summary, Montreal International Airport. Environment Canada, Montreal

Andrey J, Olley R (1990) Relationship between weather and road safety: past and future research directions. Climatol Bull 24(3):123-137

Bertness J (1980) Rain-related impacts on selected transportation activities and utility services in the Chicago area J Appl Meteorol 19:545-556

Bordeleau B (1993) Les coûts de l'insécurité routière et de la prévention au Québec en 1991. Lettre de sécurité routière, Hiver, 1993. SAAQ, Québec

Brotsky H, Hakkert AS (1988) Risk of a road accident in rainy weather. Accid Anal Prev 20(3):161-176

Editorlal responsibility: Chris de Freitas, Auckland, New Zealand
Campbell ME (1971) The wet pavement accident problem breaking through. Traffic Q 25:209-214

Codling PJ (1974) Weather and road accidents, In: Taylor JA (ed) Climatic resources and economic activity. David \& Charles Holdings, Newton Abbot, p 205-222

de Freitas CR (1975) Estimation of the disruptive impact of snowfalls in urban areas. J Appl Meteorol 14:1166-1173

Haghighi-Talab D (1973) An investigation into the relationship between rainfall and road accident frequencies in two cities. Accid Anal Prev 5:343-349

Montréal ville de (1992) Etat de la situation du déneigement à Montréal. L'équipe du plan directeur de gestion intégrée du déneigement. Service des travaux publics, Montréal

Moore AB, Humphreys JB (1972) High speed skid resistance and the effects of surface texture on the accident rate. In Symposium on skid resistance of highway pavements American Society for Testing and Materials, Philadelphia

Orne DE, Yang AH (1972) An investigation of weather factor effects on traffic accidents. Traffic Eng 43:14-20

Palutikof JP (1991) Road accidents and the weather. In: Perry AH, Symons LJ (eds) Highway meteorology. E\&FN SPON, London

Québec, Transports du Québec. Service des Projets (1992) Recensement de la circulation sur les routes du Québec; rapport annuel. Direction des communications du Ministère des Transports du Québec, Québec

Québec, Direction du soutien à la qualité des infrastructures (1993) Guide de viabilité hivernale. Direction des communications du Ministère des Transports du Québec, Québec

Rooney JF Jr (1967) The urban snow hazard in the United States. Geogr Rev 57:538-559

SAAQ (1993) Nombre d'accidents survenus sur l'ile de Montréal en 1990, 1991 et 1992 en fonction de la gravité et de la date d'accident. Societé de l'Assurance Automobile du Québec, Direction de la Statistique, Québec

Satterthwaite SP (1976) An assessment of seasonal and weather effects on the frequency of road accidents in California. Accid Anal Prev 8:87-96

Sherretz LA, Farhar BC (1978) An analysis of the relationship between rainfall and the occurrence of traffic accidents. J Appl Meteorol 17:711-715

Smith K (1982) How seasonal and weather conditions influence road accidents in Glasgow. Scottish Geogr Magazine 98: $103-114$

Veith AG (1983) Tires, roads, rainfall, vehicles: the traction connection. In: Walter JD, Meyer WE (eds) Frictional interaction of tire and pavement. ASTM Publications, Philadelphia, p 3-40

Submitted: January 7, 1997; Accepted: August 6, 1997 Proofs recelved from author(s): September 29, 1997 